reviewer (pp. 503-5, October 14, 1904) with the greater part of whose remarks he is in cordial agreement, and whose work he has ever found to be characterized by the greatest care and the fullest consideration of every point.

My endeavor has been throughout to clearly show the species and to some small degree their variation, vegetative, continuous and discontinuous. My reason for not publishing in detail my observations on the influence of environment on mode of growth of corals was simply lack of means to pay for the necessary illustrations. I kept careful records of a considerable number of species for this purpose, but on reconsideration now $\mathrm{I}$ am of opinion that any account, or at least the first account, of the same should be written while still on the reef and capable of verifying any point that may arise. The best way would be to take the necessary physical observations in three or four different environments containing the same species of corals, to carefully chart the character and organisms of the same, and to show photographically their variations. The specimens, from six or eight square yards of each, being subsequently mounted in the positions in which they grew in respect to one another and other organisms, would form most instructive and unique exhibits in any museum which had the funds and enterprise to undertake such a work. The best locality would undoubtedly be the West Indies, since its broader physical conditions are, perhaps, better known than those of any other suitable coral-reef region, and because it is the home round which coral literature is entwined.

I used the term continuous in respect to variation in its ordinary sense, excluding, however, vegetative variation, that due to the action of the environment on the organism during its growth. I do not restrict the term to series from one locality grading into those from others, as it may be equally well seen in series from one locality, or even from one environment of the same. Where the modes of series from diverse localities differ in certain characters from one another, as seems to me frequently to be the case, and yet the individual specimens of the different species merge, we would seem to have before us true cases of natural selection acting on continuous variation. Yet-and this is the pointneither new species nor new genera seem to result from this action.

In attempting to adopt a classification more in accordance with our present ideas than that of Duncan, I found that I had in the works cited by Mr. Wayland Vaughan less than a quarter of the information required to turn out a 'good job,' and less than a sixth of the necessary specimens in Cambridge required to complete the other three quarters. Under the circumstances I treated each genus by itself, satisfying myself first as to its validity, merely adopting a well-known order for convenience of reference. I tried to lay the foundations in the species themselves, and I left the gross classification in the hope that some one, who has the specimens-I know no one more capable and with wider knowledge of recent and fossil corals than your reviewer -might be induced to consider the whole. Further, in the present state of our knowledge I found it hopeless to work out a scientific classification, based, as I consider such must be, on the polyphyletic origins of the socalled astræid, fungid and perforate groups.

I have no doubt Mr. Wayland Vaughan is correct in respect to the generic names to which he refers. I have, however, considered the identity of Mussa with Symphyllia and of Coloria with Macendrina, and in spite of Professor Verrill's and Mr. Wayland Vaughan's opinions I still separate them; the anatomy and development of their polyps and coralla should be compared and would settle the question. J. Stanley Gardiner.

Cambridge, England.

\section{SOME FURTHER COMMENTS ON THE GUATEMALAN BOLL WEEVIL ANT.}

IN his reply to my remarks on the feasibility of establishing the Guatemalan boll weevil ant in Texas, Dr. O. F. Cook shows how dubious are the claims for the muchadvertised efficiency of this insect. Clearly there are two distinct problems involved in the discussion; first, the establishment of the boll weevil ant in the southern states, and 
second, its efficiency as a boll weevil destroyer. My paper dealt largely with the former, since it is, of course, the conditio sine qua non of the latter problem. Dr. Cook calls my remarks a 'post facto prognosis,' wishing, I suppose, to create the impression by this contradictio in terminis, that his Schmerzenskind, the kelep, to which the Department of Agriculture has been standing sponsor, is doing remarkably well. I will pass over the fact that this implication is hardly borne out by the latest reports from the field of experimentation, and consider some of Dr. Cook's statements.

He says that 'it was obvious to Professor Wheeler from the first that the case was hopeless.' This statement is false, inasmuch as neither I nor anybody else outside of the Department of Agriculture could have had any opinion on this subject till very recently, for the very simple reason that the scientific name of the ant was not made public by the Department till its great value as a boll weevil destroyer had been boomed in all the newspapers of the country. The kelep, as Dr. Cook informs us, was discovered 'on the cotton April 20, 1904, in Alta Vera Paz, Guatemala, and its efficiency as a destroyer of the Mexican cotton boll weevil was demonstrated the following day.' But even in his official report, which could hardly have been published before August 1, the scientific name of the ant was not given and it was several weeks later before I could ascertain it.

Dr. Cook further says that I have disregarded 'several facts which might have mitigated the confidence of the prophesy.' The first of these is a straw fact of Dr. Cook's own manufacture, namely the supposition that I am of the opinion that Ectatomma is very much like Odontomachus.* I am at a loss to

* Dr. Cook is ' ready to follow Mayr and Ashmead in assigning these genera to separate families.' In other words, the genus Odontomachus should be separated from the Ponerinæ (or Poneridæ as Cook and Ashmead persist in calling the group) and made the type of a distinct family, the Odontomachidæ. This was Mayr's opinion many years ago, but it is probable that he now believes with the eminent myrmecologists Fmery and Forel that Odontomachus (together know how I could have given this impression, as the only time' $I$ associated these genera directly was when I considered Odontomachus to be more dominant, more variable and more widely distributed than other Ponerinæ, Ectatomma, of course, included. This statement has not even been met, to say nothing of having been refuted, by Dr. Cook.*

It is, in fact, Dr. Cook himself who should be glad to have the kelep more like Odontomachus. At any rate, he makes a futile attempt to show that the kelep is a dominant, 'enterprising' ant, with large colonies (i. e., prolific) and highly adaptable. But closer examination shows that the kelep is like the other Ponerinæ in being below par in all of these respects. It is 'dominant' only in the cotton fields of Guatemala, and very rare or absent elsewhere in that country. It is ' enterprising' although ' compared with the nervous haste of many other species, its motions

with Anochetus and Champsomyrmex) can not be separated as a distinct family, but has hardly more than tribal value. The only characters on which such a separation could be effected are the peculiar shape of the petiole and mandibles. But the very same kind of a petiole is found in certain undoubted Ponerinæ, like the South American Leptogenys unistimulosa, and if the shape of the jaws is such an important character, we should have to make several families out of such genera as the myrmicine Strumigenys, some species of which, like S. louisiance, grandidieri, etc., have mandibles very much like Odontomachus. But this would be absurd, hence it is best to let well enough alone. Moreover, the shape of the mandibles in different genera of the Ponerinæ (e. g., in Harpegnathus, Thaumatomyrmex, Mystrium, etc.) is so diverse that this subfamily would have to be resolved into a great number of families, if we were to follow Cook's example with Odontomachus. Undoubtedly this would give a fine opportunity for a display of the mihi itch, but the cause of science would be little furthered thereby.

* The larva of Ectatomma is much more primitive in its characters than that of many other Ponerinæ, whereas the larva of Odontomachus is much like that of the typical genus Ponera. This fact, too, has an important bearing on the 'taxonomic position of odontomachus discussed in the preceding foot-note. 
are slow and deliberate (sic!), and, like the so-called praying mantis, it stands for long periods quite motionless, with the antennæ and mandibles extended, ready for something to come that way and be caught.' This must be 'enterprise' as understood by the Jewish tailor of the comic papers who stands in the doorway of his shop waiting for customers.

It seems that I was mistaken in supposing that the colonies of the kelep contain only from 20 to 110 workers, though these numbers were taken from Dr. Cook's own statement concerning the colonies introduced into Texas. We are now told that they (not the colonies in Texas!) comprise between 200 and 300 individuals and that 'there are seldom less than 100 and sometimes 400 or more.' Now even if we put the number at 500, these are still very small colonies, as ant colonies go, and show conclusively that the kelep, like other Ponerinæ, must be either short-lived or much less prolific than other ants, or both.

The adaptability of the kelep, according to Dr. Cook, is 'shown by its association with the cotton for the sake of its nectar, as well as by its skill in stinging the boll weevil.' If this shows anything it does not show adaptability but adaptation, which is a very different matter. The first part of Dr. Cook's statement, together with several of his previous statements, implies that the cotton plant and the kelep live in a state of symbiosis, like that which has been claimed to exist between the South American Cecropia tree and the ant Azteca instabilis, and between the African and tropical American acacias and the species of Sima and Pseudomyrma respectively. These classical cases, however, have never been demonstrated to the satisfaction of either the botanists or the myrmecologists. Any one who observes without bias the insects visiting many plants with extra-floral nectaries, like our species of Cassia, Ricinus, Stillingia, Populus, etc., will find that certainly in such cases no symbiosis exists. Not only do all sorts of ants, mutillids, bees, wasps, beetles, flies, etc., visit the extra-floral nectaries, but caterpillars, chrysomelid larvæ, etc., may be found feeding with impunity on the lacerated foliage of the plants thus 'pro- tected.' It is possible, of course, that some of the cases of so-called ant and plant symbiosis may be genuine, but before any such statement can be made of a particular case like the cotton plant, we need much more concise, abundant and painstaking observations than have been published hitherto.

I fail to see, therefore, that Dr. Cook has produced any facts that could lead me to ' mitigate' the statements made in my former paper. The kelep is a typical ponerine ant, with all the disadvantages of a fixed and archaic constitution in the presence of experiments that require for their successful execution a plastic and adaptable species. When the kelep has succeeded in becoming a thriving component of the Texan ant fauna there will be time enough to determine whether its strenuous and enterprising efforts can 'add even ten per cent. to the cotton crop'-we will not expect it to chase all the boll weevils into the Gulf of Mexico. Dr. Cook himself admits that "the chances are still very much against it, no doubt.' This is exactly what I have maintained. Neither I nor any one else blames the Department of Agriculture for following every clue till some ' concrete conclusion' is reached, but the premature and persistent booming of a conclusion which is far from being 'concrete' and has 'chances very much against it' can only discredit the Department of Agriculture, Dr. Cook and the unsuspecting kelep in the eyes of the general public, the Texan cotton grower and the scientist. I shall have no further remarks to make on the kelep and am satisfied to await patiently the concretion of the conclusionseven till the Greek calends.

\section{William Morton W HeEler.}

\section{ARE THEY SYMPATHETIC DRUMS ?}

To the Editor of Science: Some of the African xylophones (marimbas) and those of Central America, which negro slaves introduced there, have resonators-gourds, or cylinders of cane or of bamboo, placed beneath each sounding-bar. Often at the lower end the side of each resonator is pierced with a lateral hole and covered with a thin film or membrane. I have never found a reasonable ex- 